\title{
The Policies of Provision of Assistive and Welfare Technology-A Literature Review
}

\author{
Katarina Baudin * ${ }^{\mathbb{D}}$, Maria Mullersdorf, Angelina Sundstrom ${ }^{\circledR}$ and Christine Gustafsson \\ School of Health, Care and Social Welfare, Malardalen University, 72123 Västerås, Sweden; \\ Maria.mullersdorf@mdh.se (M.M.); angelina.sundstrom@mdh.se (A.S.); christine.gustafsson@mdh.se (C.G.) \\ * Correspondence: katarina.baudin@mdh.se
}

Received: 10 December 2019; Accepted: 20 February 2020; Published: 24 February 2020

\begin{abstract}
Background: Due to the increasing ageing population worldwide, humanity is facing global demographic challenges. For many people, their later years are often lived with changed functioning and the need for support in daily living activities. Assistive technology and welfare technology (AT/WT) constitute a partial solution to the demographic challenges. Objectives: The purpose of this literature review is to identify the policy features, such as decision models and guidance for the provision of $\mathrm{AT} / \mathrm{WT}$ as reported in the current scientific literature. Methods: A literature review with a deductive approach using the structure of the Global Cooperation on Assistive Technology (GATE) model was conducted. The data were searched from the databases: PubMed, Cinahl Plus, and the Web of Science, resulting in nine included articles. Results: The findings are presented according to the structure of the eight domains from the GATE model - policy, assessment, procurement, technology, environment, usability, sustainability and rights- which are further grouped into categories exploring the variations in every domain. Conclusion: The review reveals a nascent and growing interest in the area; however, evidence-based decision models and other guidance on AT/WT are lacking. Recent scholarships and policy reforms can form the basis of stronger guidance to organise complex AT/WT systems, but further and future research is needed.
\end{abstract}

Keywords: assistive technology; welfare technology; telemedicine; telehealth; decision making/decision-making process; health policy; policy making

\section{Introduction}

As the ageing population grows, the demographic changes will increase the need for healthcare services; however, the number of people who should provide and finance these services is decreasing [1-3]. Health technology, such as assistive technology (AT) and welfare technology (WT), has been launched as an important measure to meet some of these challenges [2,4]. The resources that will cover healthcare and technology expenses are scarce, and the decision makers have a challenging task. Despite the high level of awareness of the economy in healthcare, decisions often have to be made quickly, taking other factors into account, thus limiting the use of economics [5]. Health policies concerning the AT/WT provision systems pose a complex challenge, and the process in the AT/WT field needs to be evidence-based, transparent and flexible, since no single solution exists.

\subsection{Assistive and Welfare Technology}

The AT field has experienced many changes and considerable growth, and the technology development has accelerated for people with disabilities, chronic illnesses and changing needs due to ageing. The term, AT, embraces universally designed, as well as everyday and mainstream products, remote technologies, monitoring and sensing devices, and a variety of information and telecommunication technologies [1]. Due to these technologies being designed for people with diverse 
functioning abilities, a multitude of low- and high-technology devices are available [3]. The use of AT is suggested to help people and treat different chronic diseases (that arise from the ageing society) [6] with the use of sensors, GPS alarms and reminders [2,4,7]. Definitions of AT and WT vary and continue to evolve. The World Health Organization's (WHO) definition of AT was extended in 2016, qualifying that AT "promotes well-being" and supports "persons with disabilities to live healthy, productive, independent and dignified lives (and) participate in education, the labour market and social life." AT can reduce the need for formal health and support services, long-term care and the burden of caregivers. Without AT, people with disabilities, older people and others, risk exclusion, isolation and poverty. The burden of morbidity and disability increases [8].

In the Scandinavian context, WT is a well-known concept; however, it is complex, and evolved from merely an application to include applications, administration services and systems [9]. According to the Swedish Agency for Participation's (2019) definition, "Welfare technology is a digital technology with the purpose to maintain or increase security, activity, participation or independence for a person with or elevated risk for a disability." The definition of WT includes both technology devices and intelligent systems. To encompass the demographic changes worldwide, this area has expanded, and WT has been launched in the Scandinavian context as a solution to several problems $[2,4,10]$.

\subsection{Health Policy and Guidance}

The rapid development of the technology and the changes in society with scarce resources are challenging to decision makers and the provision of AT/WT. Health policy is a general statement of understanding and guiding decision making that results from a deletion among relevant partners on the issues according to the WHO Health Systems Strengthening Glossary. Health policy includes a set of decisions or commitments to pursue courses of action aimed at achieving defined goals for improving health and stating the values underpinning these decisions [11]. AT/WT and related fields have been neglected in health policies, and a modest literature base guides policy reforms at this time of dynamic growth in the AT sector [12]. There is evidence of how specific products support people at the biological level; the challenge is to understand what works at the system and the policy levels, where there is a clear paucity of literature $[1,13]$.

\subsection{Rationale}

To the best of our knowledge, few studies have been conducted in the field of health policies, such as guidance for the provision of AT/WT. Under a welfare system with tax-funded AT/WT, reliable and evidence-based processes and models are required to support the decisions. We strive to obtain a deeper understanding of the processes in determining, providing and implementing AT/WT by reviewing the scientific literature in this important yet neglected field. Our study aims to identify the policy features, such as decision models and guidance for the provision of AT/WT, as reported in the current scientific literature.

The Global Cooperation on Assistive Technology (GATE) model proposed by Khasnabis et al. [14] is used in this study as a lens to grasp the area. The GATE model was recognised by the WHO after a meeting to increase access to high-quality, affordable AT in order to fulfil the obligations of the Convention on the Rights of Persons with Disabilities (CRPD) [15]. The GATE model introduced by Khasnabis et al. [14] is a modification of the original one and consists of eight key questions or domains: policy, assessment, procurement, technology, environment, usability, sustainability and rights.

\section{Method}

A qualitative deductive approach [16] was used by applying the GATE model [14] to understand and describe health policies and guidance for the provision of AT/WT. A literature search was conducted between February 2017 and April 2018 in the Cinahl plus, PubMed and Web of Science databases, including articles published between 2000 and 2018. To identify relevant studies, the search terms were assistive technology/devices, welfare technology, information and communication technology 
(ICT), telemedicine, telehealth, decision making/decision-making process, health policy/policies, policy making and ageing. Database searches were repeated until no new articles and inclusion criteria were found. This resulted in 2123 hits (Figure 1). Duplicates were removed, and abstracts were then reviewed by the authors; those identified as relevant to the review were selected for retrieval and review of their full texts. The inclusion criteria were as follows:

(1) Written in English

(2) Published between 2000 and April 2018

(3) Peer reviewed and

(4) Including different decisions/models/theories/guidance/policies regarding

(5) Health technology, assistive technology/devices and/or welfare technology, telehealth or ICT.

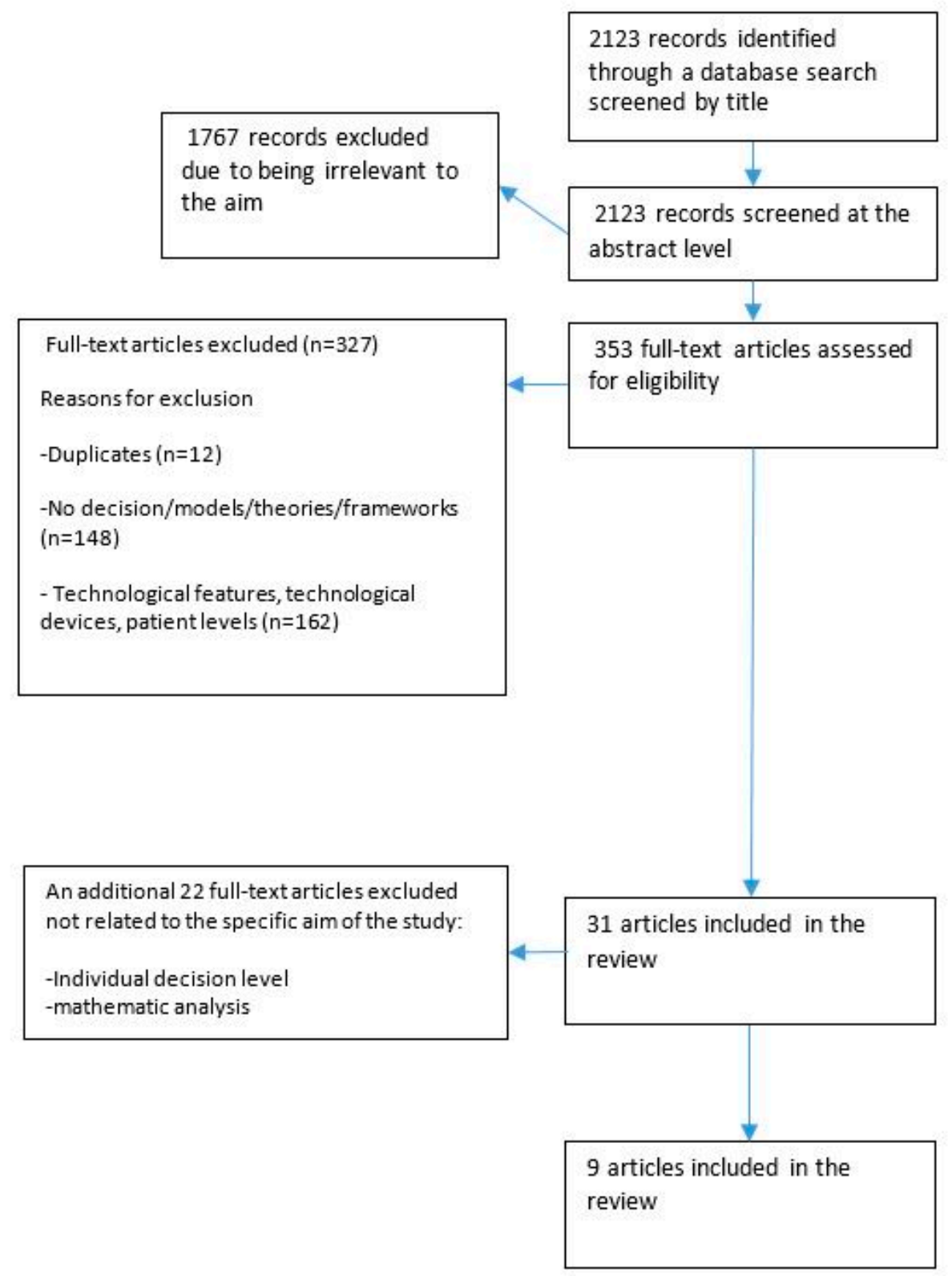

Figure 1. Flowchart of the inclusion and exclusion process.

Only studies on the decision-making processes and/or health policy at a societal level were included, not those focused on decisions at the individual AT/WT user level. The search was limited to 
the most recent developments in this field. The exclusion criteria were reviews, mathematical models or patient involvement, duplicates, technological features and mathematic cost analysis. A manual search of the reference lists of the included articles was also conducted. In total, nine articles were included in the review (see Appendix A). Literature reviews sometimes employ quality evaluation methods to assess the strength of evidence of the outcomes reported by the included papers. However, in this review, we did not focus on the reported study outcomes but on the process, the models or the guidance. Hence, we did not conduct a separate quality evaluation but strived to achieve a high quality of the included studies by means of the rigorous eligibility criteria and search strategies outlined above.

The included articles vary in their types, designs and methods, including published conference proceedings, position papers, workshops, questionnaires, interviews and different theory applications.

\section{Study Selection and Qualitative Analysis}

To retrieve the relevant data from each article matching the inclusion criteria, a template was developed to guide the extraction process (Table 1). The template depicted the included article's content, referring to the GATE model [14] including the eight domains (policy, assessment, procurement, technology, environment, usability, sustainability and rights).

Table 1. Template of each included article's content, referring to Khasnabis et al. [14].

\begin{tabular}{|c|c|c|c|c|c|c|c|c|c|}
\hline $\begin{array}{l}\text { Domains According } \\
\text { to Khasnabis et al., } \\
\text { 2015: }\end{array}$ & $\begin{array}{l}\text { Kidholm et al. } \\
2012\end{array}$ & $\begin{array}{c}\text { de } \\
\text { Witte et al. } \\
2018\end{array}$ & $\begin{array}{l}\text { Layton, } \\
2015\end{array}$ & $\begin{array}{l}\text { Durocher et al., } \\
2017\end{array}$ & $\begin{array}{c}\text { Andrich et al., } \\
2013\end{array}$ & $\begin{array}{l}\text { MacLachlan } \\
\text { \& Scherer, } \\
2018\end{array}$ & $\begin{array}{l}\text { MachLachlan et al. } \\
2018\end{array}$ & $\begin{array}{l}\text { Lersilp et al. } \\
\quad 2018\end{array}$ & $\begin{array}{c}\text { Henschke } \\
2012\end{array}$ \\
\hline Policy & $x$ & $\mathrm{X}$ & - & - & $x$ & $x$ & $x$ & $\mathrm{x}$ & $x$ \\
\hline Technology & $x$ & - & $x$ & - & $x$ & $x$ & - & $x$ & \\
\hline Environment & $x$ & $x$ & - & & $x$ & $x$ & $x$ & $x$ & $x$ \\
\hline Usability & $x$ & $\mathrm{x}$ & - & - & $x$ & $x$ & $x$ & $x$ & $x$ \\
\hline
\end{tabular}

The methodological approach was deductive, and the analysis used a qualitative descriptive method [16]. In the first step, the text was read by two of the authors (K.B. and C.G.) to obtain an overall picture of the material, and this was repeated several times. In the second step by using deductive approach, the data were reduced to their essential content, in accordance with the eight domains [14]. In the third step, the extracted findings were examined and analysed in relation to their similarities, differences and variations in the two authors' categorisations. In the final step, the authors (K.B. and C.G.) reached a consensus to resolve their variations and classified the contents under the eight domains [16].

\section{Results}

The results of the qualitative descriptive analysis are presented using the structure of an initial short description of each domain [14].

\subsection{Policy}

The policy domain covers the existence and aspects of a national policy on AT/WT [14]. Seven of the reviewed articles [12,17-22] have policy content. The overarching and common finding regarding AT/WT policies is that they constitute a complex area without guidance. Without any national policy, decision-making processes are long and complicated, which has a negative impact on the provision of AT/WT [18,21,22]. The consequences of the lack of national AT/WT guidance could include both inappropriate treatment and time delays. de Witte et al. [18] state that AT/WT guidance could be the mechanism that would determine who would be entitled to obtain AT/WT. For example, many countries rely on medical definitions and diagnostic criteria to determine AT/WT eligibility. In contrast, some authors argue that ethical, social and legal aspects are pinpointed as important factors before even considering and introducing AT/WT in healthcare [12,17]. 
The included articles also highlight that legal rights require equitable access to AT/WT. AT/WT policies should be well-coordinated with well-functioning infrastructure and accessibility policies for products, services and environments that are user-friendly and inclusive. MacLachlan and Scherer [19] remark that AT/WT policies could be explicit from a system perspective, with a wider policy effort to increase the well-being of the whole population. National AT/WT policies, combined with other policies across different sectors, highlight the resource implications and funding requirements and present an integrated population-level approach, based on widely accepted and realistic principles of equity. Furthermore, policy embraces a lifelong approach, where users' needs-as they make the transition across life stages_are met in a seamless (and more cost-effective) manner [19].

Organisational aspects are complex due to different organisations and local systems. Lersilp et al. [20] classify three main related organisations providing AT/WT: local community hospitals, district hospitals and sub-district municipalities. These organisations have different local policies under different provincial health offices, and even if persons with disabilities have legal rights, there are still limitations due to government budgets. Although there is a related regulation and an AT/WT provision system, many types of AT/WT products are not used by the patients/clients, and some are not even received in the patients' homes [20]. The connection among policy, strategy and action plans should be flexible at two levels-operationally (functions are performed), as well as locally and regionally - ensuring effective mechanisms for national policies to successfully work in often quite different subnational contexts. This means that the same services are delivered in somewhat different ways and perhaps by different organisations, groups or individuals in different places [20,21].

The findings also emphasise the aspects of the challenges in providing good and structured AT/WT policies. AT/WT cuts across all sectors and ages, and it is paramount that policy initiatives recognise and reflect this rather than silo it [21]. A policy must be implemented across all sectors, in the same way that people live across all sectors. Another challenge is that the policy also needs to consider the whole lifespan approach to people's lives and include all AT/WT devices, from walking sticks to advanced digital devices [21,22].

\subsection{Assessment}

In a good service delivery system, skilled and competent staff are necessary to assess the needs of patients and prescribe AT/WT [14]. In this regard, the assessment domain concerns the issue of sufficient competence in providing care for patients. This domain is included in seven of the reviewed articles [12,17-19].

Sufficient competence, skills and knowledge in responding to users' needs, the use of standards and regulations, the search for available information, and the proficiency to learn from feedback are crucial. In the reviewed articles, it is concluded that competence could entail both the experience and the skills necessary to serve the users, elements of education, as well as the possibilities for further education. Therefore, the provision of AT/WT has to be centred on the individual needs of users, and qualified practitioners should establish the individual assessment of disorders, including the potential use of AT/WT. AT/WT providers have to continue these assessments by documenting the explicit provision of AT/WT $[12,17,18,22]$. If AT/WT means advanced ICT, there is a need for new specialised professionals in certain areas (e.g., ICT-based AT/WT) [12].

The findings in the literature also reveal specialised AT/WT centres for quality assurance, improved provision, security, lending/recycling, efficiency and equality processes. Such centres can provide services to municipalities, flexible teleservices and similar technological support [17-20,22]. A long-term process increases the quality of assessment, the provision of products, evaluation and support at both individual and broader levels $[19,22]$. The AT/WT assessment centres could address more complex needs and be places characterised by competence, experience and information exchange among companies, professionals and users [12,19-22]. Lersilp et al. [20] conclude that there is a need to improve the AT/WT provision system. Similarly, Henschke [22] pinpoints the importance of all stakeholders' participation in the process at all levels to provide AT/WT services. 


\subsection{Procurement}

The procurement domain relates to opportunities to provide quality and affordable AT/WT [14]. The concept of procurement is mentioned in seven of the reviewed articles [12,17-22].

Efficiency in the system pinpoints the complexity of regulations, procedures, the control of the system over the process, the mechanisms that are able to control costs and effectiveness, and the delegation of decision-making power [18]. Effective systems in AT/WT include structured ways to meet face to face and should be designed to connect developers and users in such a way as to facilitate innovation based on real user needs captured in the field [17,18]. The importance of user influence is argued, with a functional technical solution for the users, as something that can be facilitated by end-user involvement $[12,19]$. User involvement is multifaceted, including how much the product costs, the supplement structure aligned with development and innovation, which products are needed, production costs, and supply and sufficient demand data aligned with product development and innovation [19]. The user influence and patient perspective on AT/WT research and development can be organised at three levels: mechanisms to systematically collect individual user feedback (e.g., through panels of expert users), user involvement in specific projects, and user involvement in defining priorities in research and development programmes [12].

The availability of AT/WT and a service delivery system's accessibility, in a way that no one is excluded or discriminated from the services, are also important findings. The service delivery system needs to be coordinated at three levels: first, around the user; second, aligned with the process undergone by the users and the policies regarding AT/WT; and third, involving the support of users (e.g., relatives or professional caregivers) $[12,18,19]$. With sufficient access to the service delivery system and the provision of AT/WT, the assessment should be based on individual needs, regardless of gender, age or disability. It should be easy to gain access to the system and start the procedure. General information is crucial for users to know that AT/WT is available [18,19] and should be offered and accessible to all potential users. Information centres should be located in relevant places close to citizens (public places, geographic areas, homes, etc.) to increase availability. MacLachlan and Scherer [19] state that procurement is about purchasing, and at the national level, this concerns AT/WT purchases and meeting the needs of the population, whether the products are manufactured in the country or imported. There is also emphasis on problems associated with the provision of AT/WT, meaning difficulties related to AT/WT providers, funding, physicians (medical providers), contracts between medical fund providers and AT/WT suppliers [22]. The other pinpointed problems are limited choices of AT/WT, delivery procedures and issues in determining AT/WT requirements. The distance to AT/WT centres is another mentioned problem [22].

\subsection{Technology}

The technology domain reveals AT/WT's reliability or sufficient function [14]. Four of the reviewed articles $[12,17,20,21]$ include the concept of technology and AT/WT. According to Kidholm et al. [17], the technology could be perceived as a safety concern when considering technical and clinical safety and reliability for both patients and staff. The technologies used in the AT/WT systems are multifaceted and include what is needed by the users, which products are updated, as well as supply and demand in consumer markets [21]. The technology domain includes AT/WT with both low- and high-technology (hereafter, low-tech and high-tech) functions. Low-tech AT/WT devices include canes, crutches, walkers, wheelchairs and adaptive tricycles. Lersilp et al. [20] conclude that the most commonly used AT/WT devices are low-tech, recycled, second-hand (57\%) and borrowed ones. Other articles [12,17] mention technology deployment and a new specialised area-high-tech AT/WT and ICT products. Development in collaboration with new or specialised professionals is also required in this specific ICT and AT/WT area [12,17]. 


\subsection{Environment}

This domain covers environmental aspects of AT/WT [14]. The concept of the environment is included in seven of the reviewed articles [12,17-19]. Environmental support, in this context, refers to the infrastructure for maintenance and repair, meaning that there has to be an appropriate infrastructure to support the use of AT/WT for both primary users and the staff in order to ensure that the products and the services continue to meet the needs of the end users [17,18]. As MacLachlan et al. [21] argue, the support system must follow the users throughout their lifetime, with the expected concurrent changed needs. The environment around the provision of AT/WT could be identified as space, which refers not only to the physical setting but also to the societal infrastructure within it, such as the government, health policies and institutions, as well as the psychosocial and the cultural contexts [19]. The focus is on the entire context, where both the resources and the challenges in the setting are included. Physical environments and social spaces are designed for universal access, considering the need for access of all users [12,19,21,22].

\subsection{Usability}

The usability domain refers to AT/WT users' satisfaction and the products' usefulness and effectiveness [14]. In six of the included articles, the usability concept is discussed [12,17-21].

The patients' perspective is also described in the literature and is related to the perception on the actual technology device/artefact $[17,18]$. By considering the users' perspective, the AT/WT products and solutions can include flexibility and compliance to the requirements of both users and caregivers [12,19].

With a user involvement approach, the user is a partner in the process. The user is the best judge of whether a specific technical solution to an operational limitation is functioning. The individual AT/WT plan should revolve around the life goals that the user wants to achieve. A good process is designed to empower users to make their own choices, and the users should be assigned an active role throughout the process $[12,18,19,21]$. Usability could also be understood as clinical effectiveness from a health diagnosis perspective; for example, effects on the users' health, effects on their health-related quality of life as a behavioural outcome, the usage of health services, satisfaction and acceptance, understanding information, empowerment and self-efficiency [17]. Users should be involved in all aspects of the provision of AT/WT and in their own process of using AT/WT in their daily lives [18,20,21]. The lack of this involvement increases the risk of wrong or ineffective interventions, the abandonment of the provided AT/WT and the waste of resources. Several researchers conclude that user influence exists at all levels, as a legal protection of users' rights, the involvement of users at a health policy level and the users' influence on decisions in the AT/WT procurement process [12,18].

\subsection{Sustainability}

The sustainability domain is broad and involves sufficient resources to support the maintenance of AT/WT [14]. Sustainability includes climate factors, such as respect for nature, as well as economic justice and universal human rights. Six of the included articles mention sustainability in different ways [12,17-21].

The economic perspective on resources emphasises sustainability when delivering AT/WT. Additionally, the related changes in the use of healthcare are highlighted, such as management, organisational structure, and ethical, legal and social issues $[12,17,19,21]$. The findings reveal that the system is efficient when using available and sustainable resources in the shortest amount of time and at the lowest cost. The elements of efficiency are complex and include many factors, such as regulations, procedures, different mechanisms that are able to control costs and effectiveness, and finally, the power of decision making at an appropriate level of competence $[12,18,20]$. 


\subsection{Rights}

The rights domain extends over the exploration of AT/WT as a human right in facilitating independence in daily life or social participation [14]. The concept of rights is mentioned in eight of the reviewed articles [12,17-19,21-24]. Inclusion and participation in society are important human rights and could be facilitated by AT/WT $[12,17-19,21,23,24]$. One challenge that arises is the complexity of different financial contracts in the provision of AT/WT. Different welfare systems limit patients' access to specific AT/WT or healthcare providers. Other aspects to be aware of involve gender issues and rural area residents who are unable to travel long distances. The AT/WT market is not open, in the sense that end users generally have limited decision-making power when selecting among devices [12,21-24].

Financial hindrances and different welfare systems are also argued. One of the major concerns is how users finance AT/WT devices. The users should have the right to appeal, and there should be no financial hindrance for those who need an AT/WT device. Two of the included articles also point out that service delivery systems should be designed in such a way as to maximise individual outcomes and minimise costs [12,18]. Kidholm et al. [17] also highlight the existence of sociocultural, ethical and legal rights. Sociocultural rights include social and cultural arenas where the users live and act while using AT/WT products. An ethical aspect is involved when the use of an application itself and the consequences of not implementing it must be addressed.

\section{Discussion}

Our study aims to identify the policy features, such as decision models and guidance surrounding the provision of AT/WT, as reported in the current scientific literature. With the deductive approach, the GATE model [14] is used as a lens and a structure to capture and understand the decision-making processes and the health policies surrounding AT/WT and its provision system. One aspect of the model has facilitated the understanding of the area, and another aspect has made the literature search more critical compared to standard reviews, resulting in nine articles. Some of the major findings are highlighted and discussed below.

One important finding is the environment domain, which is important for health and healthy ageing. The different variations that have emerged from the analysis include environmental support and space, settings and infrastructure. In the Nordic countries, the policy emphasises using AT/WT to enable and support older people to stay and live at home [25]. For example, "smart homes" might enable older people with different impairments to participate in the daily living and increasingly use smart technology to support them with the connected technologies integrated into the buildings [26]. Other examples are primary healthcare facilities, which need to be accessible to older patients using AT/WT. Older people comprise a large group of AT/WT users and will be even larger in the future; it is important to have accessible AT/WT provision and services, in terms of both geographic location and physical accessibility [2,4,7]. Other factors are organisational readiness and employees' participation in organisational change $[27,28]$ to implement new AT/WT technologies [29]. Another aspect of the environment domain that is not visible in the analysis is Internet access. Since many modern AT/WT devices require an Internet connection, this is fundamental in equal access and usability. There are societal expectations that AT/WT and technological solutions should solve healthcare staff shortages; therefore, Internet access is important [4,10,30]. The CRPD also mandates access to good-quality and affordable AT/WT, but more than one billion people need one or more AT/WT devices, according to the WHO. Most are older people and people with disabilities, and this number will increase even more by 2050 [31]. The usability domain provides a different perspective on how much the users of AT/WT should be involved in the prescription process, and how important it is. Evidence shows that if patients are involved in the whole process and its use is followed up, the technology meets the users' needs the most [28,32]. The results of this review indicate that the usability perspective and the end-user involvement are major areas of focus worldwide [33]. These findings are also in line with the research on client-centred care, implying that patients should be active participants in the entire process, in the decision making and as active members of the healthcare organisation. Older patients 
with long-term chronic diseases become experts in their diseases. They acquire tacit knowledge over a long period of time, not only about the diseases and their symptoms, but also about the adaptation to the conditions and the difficulties in care delivery processes [34,35]. This client-centred approach in the service process is also an important factor for the satisfaction with AT/WT devices [36].

The UN's Sustainable Development Goals emphasise the need for social inclusion and making deliberate efforts to reach marginalised groups, such as people with disabilities [37]. This focus is also considered in the sustainability domain, meaning that sustainable resources should include everyone in society, and in the expectation that technological innovations, especially WT, should meet the inclusion need [38].

The rights domain includes accessibility, affordable AT/WT, financial hindrances, different welfare systems, and sociocultural, ethical and legal aspects. If accessibility to AT/WT relies on both economic and legal factors, this decreases equity and equality in accessibility in the global society $[37,39,40]$. The included articles use the theories proposed by Kingdon and Daniels in concluding that legal justice requires equitable access to AT/WT. This is also in line with the WHO's goal that equity in AT/WT should be promoted [31]. The authors write that accessible public transport is a human right and a social justice issue; however, reframing public access issues as public infrastructure and transport tasks may gain traction with governments. One solution could then be a problem reformulation, for example, "access for all", livable cities" and policy alternatives.

Another finding is the technology domain's emphasis on the importance of reliable and safe technology. We know that the technological innovations in the development of AT/WT can contribute to improving individuals' quality of life and participation in society $[3,37,41]$. The technology should also be easy to use, have quality and control security, and both understand and correspond to authentic needs. In high-, middle- and low-income countries, the access to AT/WT varies, and the policies, legislation and different programmes in health and social service systems have not responded to the increasing demand [32,42]. Health technologies, such as AT/WT, are essential to ensure that older people retain their dignity and autonomy, but the technologies' potentials and current benefits have received little attention. There is variation in how AT/WT devices are funded and provided to those who need them [32,42]. Another important aspect is that none of the included articles mentions the rapid development of technology evolving worldwide and how this might affect older people, considering the inclusion and participation aspects. One finding indicates that an important development involves the mainstream technologies; for example, smart phones and tablet computers offer features that allow them to function as AT/WT devices. It is also essential to set up both hard and soft AT/WT supply systems in the ageing society, meaning that IT support is necessary [20].

As recognised by the GATE research agenda [31], AT/WT is a priority research area that requires the involvement of all stakeholders and many different methodological approaches. AT/WT might also solve the staff shortage by freeing up more time for healthcare personnel to do duties that demand human contact and increased self-management and prolonged independence of older people [30,43,44]. A challenge is to develop health policies that ensure equitable and equal accessibility to AT/WT and prolonged independence of elderly people. It is a global challenge that differs in each country, but the question has a worldwide scope. It is also clear that the deployment of technology in different cultural contexts is not an automatic process and will likely require other approaches, such as bringing the technology to where it is needed rather than bringing the person to the technology. There are ongoing research efforts and interests in the development of AT/WT devices in many areas, especially related to dementia [45-47], which is increasing among the older population, as well as in AT provision in low-income settings where the key component is civil society $[39,40,48]$. Regarding the developing countries, it is vital to build local skills and solutions for such contexts, and further research must be done. Future studies are also recommended to deepen the existing knowledge about applicable guidance and decision-making processes in the provision of AT/WT. 


\section{Limitations}

This literature review is based on the content of only nine peer-reviewed scientific articles. Due to the approach of this work, the authors are aware about limitations in the number of included articles and thus a limited global perspective. The inclusion and exclusion criteria may have been too restrictive. However, the AT/WT organisations are required working evidence-based and, therefore, the aim of this study was to search for peer-reviewed scientific publications. A richer data for analysis might have been apparent if also including "grey literature". Further studies are needed to investigate the efficiency of systems and interventions. Another limitation is the broad concept of health technology, mentioned here as AT/WT. As written in the introduction, AT/WT is a broad field, including technologies ranging from wheelchairs to digital health technology, such as GPS or sensors. The concept of WT also remains under discussion; it is a Scandinavian concept and a recent research area. This broad scope led to a literature search with many key concepts.

The GATE model is used with a deductive approach to grasp the complex field, but it does not fit all of the eight domains (as shown in Table 2) since this study includes broader technologies. This indicates that the GATE model is appropriate for the majority but not for all. The decision-making processes in the GATE model refer to the domains of policy, assessment and procurement. When discussing guidance, these domains cover the aspects of national policies, local guidelines, individual assessments and system structures and logistics; they do not include hands-on guidance. However, this is not the model's primary aim, as the WHO launched the model as a programme to promote GATE in order to implement these aspects in the CRPD [31]. The GATE model has recently evolved and been condensed into " $5 \mathrm{P}^{\prime} \mathrm{s}$ ", focusing on the five interlinked areas of people, policy, products, provision and personnel. The GATE initiative, as a global health policy, has one exclusive goal: to improve access to high-quality, affordable, assistive products globally [31]. Another important issue in the study that should be mentioned involves the different research approaches/angles in the included material; some researchers report the problems that occurred in their research, while others collected data from workshops. The other included articles apply a theoretical approach by using theories of health, and several focus on solving problems and present different recommendations. These articles could be discussed as more or less appropriate for inclusion; however, we have included these due to the interesting and important content that they contribute, in our opinion. Another significant aspect that is noted here is that the included articles come from various countries, with different welfare, economic and healthcare systems. These global differences make the study interesting yet challenging because they might have affected the results.

Table 2. The domains and the categories that evolved from the findings in the literature review.

\begin{tabular}{cl}
\hline Domains According to Khasnabis et al. (2015) & \multicolumn{1}{c}{ Categories that Evolved from the Findings } \\
\hline Policy & $\begin{array}{l}\text { Complexity without guidance } \\
\text { Citizens' accessibility } \\
\text { Organisations and local systems } \\
\text { Challenges in providing policies }\end{array}$ \\
\hline Assessment & $\begin{array}{l}\text { Competence in meeting users' needs } \\
\text { AT/WT centres }\end{array}$ \\
\hline \multirow{2}{*}{ Procurement } & $\begin{array}{l}\text { Efficiency in the system } \\
\text { User influence } \\
\text { Availability of AT/WT devices } \\
\text { Provision problems }\end{array}$ \\
\hline \multirow{2}{*}{ Technology } & $\begin{array}{l}\text { Safety and reliability } \\
\text { Different technology levels }\end{array}$ \\
\hline \multirow{2}{*}{ Environment } & $\begin{array}{l}\text { Environmental support } \\
\text { Space, settings and infrastructure }\end{array}$ \\
\hline \multirow{2}{*}{ Sustainability } & $\begin{array}{l}\text { Patients' perspective on the devices } \\
\text { Clinical effectiveness }\end{array}$ \\
\hline \multirow{2}{*}{ Rights } & $\begin{array}{l}\text { Economic perspective on the resources } \\
\text { Sustainable resources }\end{array}$ \\
\hline & $\begin{array}{l}\text { Affordable AT/WT } \\
\text { Financial limitations and different welfare systems } \\
\text { Sociocultural, ethical and legal aspects }\end{array}$ \\
\hline
\end{tabular}




\section{Conclusions}

This literature review had the purpose to illuminate the important, although neglected, research area within health policies, such as evidence-based decision models and guidance, surrounding the provision of AT/WT. The highlighted findings in the domains of AT/WT provisions reflects a broad area in the society such as the domain of environment, the usability, sustainability and the domain of rights. One conclusion is that the domains show the complexity and challenges the societies have, with evolving systems of health care, services for community living and participation. AT/WT has expanded for people with disabilities and impairment, to those with changing needs due to ageing, and different stakeholders (clinical director, occupational therapists, rehabilitation engineer, social worker, AT users, etc.) who prioritise different outcomes regarding AT/WT. The environment domain shows the complexity of, for example, societal expectations, where the AT/WT is believed to be one solution for the growing population of older people and a step forward in the digital transformation despite the increased demand and limited resources. Another challenge is the difficulties of health technology implementation in the organisations where the readiness differs greatly between regional and municipal levels even within the same country. The importance of patient and end-user involvement in the whole process emerged in the usability domain. However, some AT/WT are too complex with multiple options or steps to follow, which complicates the use and the product is therefore discarded. Therefore, a final and sensible conclusion is that it is not possible with one global solution or decision model to cover all these challenges. Instead, we have to continue sharing research results, strategies and ideas for improvement of AT/WT provisions and services. This study shows the need for international and interdisciplinary health policies, guidelines, standards and decision models to ensure the safe progression of current AT/WT service, as well as better ways of making research applicable to users, decision makers and societies. The provision of AT/WT is important in order to ensure that the patients are provided with a product that meets their needs, and recent scholarship and policy reforms can be the groundwork for stronger guidance on these complex AT/WT systems.

Author Contributions: All authors (K.B., A.S., M.M. and C.G.) were involved in the conceptualization and manuscript writing. Data collection and analysis were performed by K.B., C.G. and M.M. K.B. and C.G. conducted the final revisions. All authors have read and agreed to the published version of the manuscript.

Funding: This research was funded by the National Network of Assistive Technology Managers (Nationella Hjälpmedelschefsnätverket), The Social Contract (Samhällskontraktet) and School of Health, Care and Social Welfare, Mälardalen University, Sweden.

Acknowledgments: We thank the National Network of Assistive Technology Managers (Nationella Hjälpmedelschefs nätverket), which contributed to this research by securing its funding. We are also grateful to The Social Contract (Samhällskontraktet) and Scool of Health, Care and social Welfare Mälardalen University, Sweden, for their contribution to this project. We also thank the editor and reviewers of Societies for valuable improvements and suggestions.

Conflicts of Interest: The authors declare no conflict of interest. 


\section{Appendix A. Appraisal of the Articles}

\begin{tabular}{|c|c|c|c|c|c|c|}
\hline Authors & Countries & Purpose & Method & Sample/Population & Type of Findings & Decision/-Theory/-Model/Health Policy \\
\hline $\begin{array}{l}\text { Kidholm, Ekeland, } \\
\text { Jensen, Rasumssen, } \\
\text { Pedersen (2012) }\end{array}$ & Norway, Denmark & $\begin{array}{l}\text { A framework for the } \\
\text { assessment of the technologies } \\
\text { is needed by decision makers } \\
\text { to assist them in choosing } \\
\text { cost-effective technologies. }\end{array}$ & $\begin{array}{l}\text { The model for the } \\
\text { assessment of } \\
\text { telemedicine } \\
\text { applications (MAST) } \\
\text { was developed } \\
\text { through workshops } \\
\text { with users and } \\
\text { stakeholders of } \\
\text { telemedicine. }\end{array}$ & $\begin{array}{l}\text { Users and } \\
\text { stakeholders of } \\
\text { telemedicine }\end{array}$ & $\begin{array}{l}\text { A model was developed, including considerations, } \\
\text { assessment and transferability assessment. }\end{array}$ & MAST \\
\hline $\begin{array}{l}\text { Durocher, Wang, } \\
\text { Bickebach, Schreiber, } \\
\text { Wilson (2017) }\end{array}$ & Canada & $\begin{array}{l}\text { By applying Daniels' theory of } \\
\text { justice to healthcare, the } \\
\text { authors argue that equitable } \\
\text { access to assistive technology } \\
\text { (AT) funding and services is } \\
\text { necessary for justice. }\end{array}$ & Daniels' theory & Not relevant & $\begin{array}{l}\text { Framework for accountability for reasonableness: publicity } \\
\text { condition, revision, regulative appeals condition. Promote } \\
\text { equitable access to goods, services at the heart of policies, } \\
\text { and in this case - AT devices and services. }\end{array}$ & $\begin{array}{l}\text { Theoretical guidance of justice in AT access } \\
\text { in the Canadian context }\end{array}$ \\
\hline $\begin{array}{l}\text { Lersilp, Putthinoi, } \\
\text { Okahashi (2018) }\end{array}$ & Thailand & $\begin{array}{l}\text { The aim is to investigate the } \\
\text { impact of the AT devices' } \\
\text { service delivery process on the } \\
\text { satisfaction with AT among } \\
\text { individuals with disabilities in } \\
\text { relation to everyday activities. }\end{array}$ & $\begin{array}{l}\text { Checklist and } \\
\text { semi-structured } \\
\text { interviews }\end{array}$ & $\begin{array}{l}\text { Nurses, physical } \\
\text { therapists, } \\
\text { administrators }\end{array}$ & $\begin{array}{l}\text { The perspectives of local policymakers and health service } \\
\text { providers indicated problems, impacts on policies and } \\
\text { ways to improve the AT provision system by applying } \\
\text { information technology. }\end{array}$ & $\begin{array}{l}\text { Information management system in health } \\
\text { districts }\end{array}$ \\
\hline Layton (2014) & Australia & $\begin{array}{l}\text { The aim is to understand the } \\
\text { complexities of AT policy } \\
\text { reform in Australia. }\end{array}$ & $\begin{array}{l}\text { Kingdon's theory } \\
\text { (2003) is applied to } \\
\text { the case of the current } \\
\text { AT policy } \\
\text { reformulation in } \\
\text { Australia (disability } \\
\text { and aged care } \\
\text { reforms) }\end{array}$ & Not relevant & $\begin{array}{l}\text { The political theory provides a way to conceptualise the } \\
\text { difficulties of consumers and AT providers' experience in } \\
\text { solutions for public policy, and having policies prioritised } \\
\text { and funded. }\end{array}$ & $\begin{array}{l}\text { Kingdon's theory (2003) as a lens to } \\
\text { understand Australian policy concerning AT }\end{array}$ \\
\hline $\begin{array}{l}\text { MacLachan, Scherer } \\
\text { (2018) }\end{array}$ & $\begin{array}{l}\text { USA, South Africa, Czech } \\
\text { Republic, Ireland }\end{array}$ & $\begin{array}{l}\text { The aim is to integrate several } \\
\text { system perspectives into a } \\
\text { single coherent } \\
\text { conceptualisation. }\end{array}$ & $\begin{array}{c}\text { Conference } \\
\text { discussion of experts } \\
\text { from the Global } \\
\text { Research, Innovation } \\
\text { and Education on AT } \\
\text { (GREAT) }\end{array}$ & Not relevant & $\begin{array}{l}\text { The } 10 \text { P's should constitute a framework for an open } \\
\text { system that can evolve and adapt, as well as empower } \\
\text { users, interconnect key components and locate these in the } \\
\text { reality of different contexts. }\end{array}$ & $\begin{array}{l}10 \mathrm{P}^{\prime} \text { s model: people, policy, products, } \\
\text { personnel, provision, procurement, place, } \\
\text { pace, promotion and partnership Open } \\
\text { system }\end{array}$ \\
\hline
\end{tabular}




\begin{tabular}{|c|c|c|c|c|c|c|}
\hline Authors & Countries & Purpose & Method & Sample/Population & Type of Findings & Decision/-Theory/-Model/Health Policy \\
\hline $\begin{array}{l}\text { McLachlan, Banes, } \\
\text { Bell, et al. (2018) }\end{array}$ & $\begin{array}{l}\text { Austria, Czech Republic, Hong } \\
\text { Kong, Italy, Ireland, South } \\
\text { Africa, India, Australia, Brazil, } \\
\text { Sweden, Switzerland, UK, } \\
\text { Ethiopia, Canada, Belgium }\end{array}$ & $\begin{array}{l}\text { The aim is to outline the key } \\
\text { principles that AT policy } \\
\text { should address and recognise. }\end{array}$ & $\begin{array}{l}\text { Discussions for the } \\
\text { GREAT }\end{array}$ & Not relevant & $\begin{array}{l}\text { There is complexity in generating policy towards } \\
\text { sustainable AT provision. The convention is rather vague. } \\
\text { The policy should promote ageing from a life-course } \\
\text { perspective, more low-tech AT, universal and } \\
\text { environmental access, and so on. }\end{array}$ & $\begin{array}{l}\text { Framework for the principles that can } \\
\text { underlie AT policies—nationally and } \\
\text { internationally }\end{array}$ \\
\hline Henschke (2012) & Germany & $\begin{array}{l}\text { The regulation in financing AT } \\
\text { devices is complex and } \\
\text { fragmented and might } \\
\text { influence their provision to } \\
\text { people who need multiple AT } \\
\text { devices. This study analyses } \\
\text { patients' problems with the } \\
\text { provision and the financing of } \\
\text { the AT devices for the ALS and } \\
\text { Duchenne diseases. }\end{array}$ & $\begin{array}{l}\text { Questionnaires and } \\
\text { interviews Content } \\
\text { analysis }\end{array}$ & $\begin{array}{l}\text { Patients (ALS and } \\
\text { Duchenne) }\end{array}$ & $\begin{array}{l}\text { Respondents experienced difficulties with the provision } \\
\text { and the financing of AT devices. }\end{array}$ & $\begin{array}{l}\text { Provision of AT devices, flows and supply } \\
\text { chain }\end{array}$ \\
\hline $\begin{array}{l}\text { Witte, Steel, Gupta, } \\
\text { Ramos, Roentgen } \\
\text { (2018) }\end{array}$ & $\begin{array}{l}\text { Australia, Brazil, UK, Ireland, } \\
\text { Netherlands }\end{array}$ & $\begin{array}{l}\text { The aim is to describe the } \\
\text { elements of the framework for } \\
\text { AT provision that could guide } \\
\text { the development of policies, } \\
\text { systems and service delivery } \\
\text { procedures worldwide. }\end{array}$ & $\begin{array}{l}\text { Based on experiences, } \\
\text { literature and inputs }\end{array}$ & Not relevant & $\begin{array}{l}\text { The authors provide recommendations to develop an } \\
\text { international standard for AT provisions. Such a standard } \\
\text { can have a major impact on the accessibility of AT for } \\
\text { people with disabilities. }\end{array}$ & $\begin{array}{l}\text { AT framework for guidance on policies and } \\
\text { so on }\end{array}$ \\
\hline $\begin{array}{l}\text { Andrich, Mathiassen, } \\
\text { Hoogerwerf, } \\
\text { Gelderblom (2013) }\end{array}$ & Norway, Italy, Netherlands & $\begin{array}{l}\text { The aim is to provide the } \\
\text { framework for exploiting the } \\
\text { potential role of AT in } \\
\text { supporting the care for and } \\
\text { participation of people with } \\
\text { disabilities and elderly people } \\
\text { through the appropriate } \\
\text { service delivery system. }\end{array}$ & $\begin{array}{l}\text { Findings from a } \\
\text { workshop }\end{array}$ & Not relevant & $\begin{array}{l}\text { The recommendations are clustered around six quality } \\
\text { indicators: accessibility, competence, coordination, } \\
\text { efficiency, flexibility and user influence. }\end{array}$ & Recommendations and framework \\
\hline
\end{tabular}




\section{References}

1. Scherer, M.J. Technology adoption, acceptance, satisfaction and benefit: Integrating various assistive technology outcomes. Taylor Fr. 2017, 12. [CrossRef] [PubMed]

2. Hofmann, B. Ethical challenges with welfare technology: A review of the literature. J. Sci. Eng. Ethics 2013, 19, 389-406. [CrossRef] [PubMed]

3. Cook, A.M.; Hussey, S.M. Assistive Technology: Principles and Practice; Mosby: St. Louis, MO, USA, 2002.

4. Søndergård, D.; Hadnagy, J.; Öberg, A.D.; Rolfer, B.; Krangnes, L.R. Välfärdsteknik handlar inte om teknik utan om människor":-Tekniksprång i nordisk demensvård. NVC Nord. Välfärdcenter/Nord. Cent. Welf. Soc. Issues. 2017. Available online: https://nordicwelfare.org/publikationer/valfardsteknik-handlar-inte-omteknik-utan-om-manniskor-tekniksprang-i-nordisk-demensvard/ (accessed on 10 December 2019).

5. Lundkvist, J. The Role of Economic Evaluation in Health Care Decision Making. Ph.D. Thesis, Karolinska Institutet, Solna, Sweden, June 2005.

6. Greenhalgh, T.; Robert, G.; Macfarlane, F.; Bate, P.; Kyriakidou, O. Diffusion of innovations in service organizations: Systematic review and recommendations. Milbank Q. 2004, 82, 581-629. [CrossRef]

7. Hofmann, B. When Means Become Ends: Technology Producing Values. Available online: http://seminar. net/images/stories/vol2-issue2/bjorn_hofmann.pdf (accessed on 10 December 2019).

8. WHO. Definition of Assistive Technology. Available online: https://www.who.int/disabilities/technology/en/ (accessed on 10 December 2019).

9. Cozza, M.; Crevani, L.; Hallin, A.; Schaeffer, J. Future ageing: Welfare technology practices for our future older selves. Futures 2018. [CrossRef]

10. Östlund, B.; Olander, E.; Jonsson, O.; Frennert, S. STS-inspired design to meet the challenges of modern aging. Welfare technology as a tool to promote user driven innovations or another way to keep older users hostage? Technol. Forecast. Soc. Chang. 2015, 93, 82-90. [CrossRef]

11. WHO. Health System Glossary. Available online: https://www.who.int/healthsystems/hss_glossary/en/ index5.html (accessed on 10 December 2019).

12. Andrich, R.; Mathiassen, N.-E.; Hoogerwerf, E.-J.; Gelderblom, G.J. Service delivery systems for assistive technology in Europe: An AAATE/EASTIN position paper. J. Technol. Disabil. 2013, 25, 127-146. [CrossRef]

13. Hamilton, J.G.; Lillie, S.E.; Alden, D.L.; Scherer, L.; Oser, M.; Rini, C.; Tanaka, M.; Baleix, J.; Brewster, M.; Lee, S.C.; et al. What is a good medical decision? A research agenda guided by perspectives from multiple stakeholders. J. Behav. Med. 2017, 40, 52-68. [CrossRef]

14. Khasnabis, C.; Mirza, Z.; MacLachlan, M. Opening the GATE to inclusion for people with disabilities. Lancet 2015, 386, 2229-2230. [CrossRef]

15. CRPD. UN Convention of Rights for People with Disability. Available online: https: //www.un.org/development/desa/disabilities/convention-on-the-rights-of-persons-with-disabilities/ convention-on-the-rights-of-persons-with-disabilities-2.html (accessed on 10 December 2019).

16. Sandelowski, M. Whatever happened to qualitative description? J. Res. Nurs. 2000, 23, 334-340. [CrossRef]

17. Kidholm, K.; Ekeland, A.G.; Jensen, L.K.; Rasmussen, J.; Pedersen, C.D.; Bowes, A.; Flottorp, S.A.; Bech, M. A model for assessment of telemedicine applications: Mast. Int. J. Technol. Assess Health Care 2012, 28, 44-51. [CrossRef]

18. de Witte, L.; Steel, E.; Gupta, S.; Ramos, V.D.; Roentgen, U. Assistive technology provision: Towards an international framework for assuring availability and accessibility of affordable high-quality assistive technology. Disabil. Rehabil. Assist. Technol. 2018, 13, 467-472. [CrossRef] [PubMed]

19. MacLachlan, M.; Scherer, M.J. Systems thinking for assistive technology: A commentary on the GREAT summit. Disabil. Rehabil. Assist. Technol. 2018, 13, 492-496. [CrossRef]

20. Lersilp, S.; Putthinoi, S.; Okahashi, S. Information management for the assistive technology provision in community: Perspectives of local policymakers and health service providers. Occup. Ther. Int. 2018, 2018. [CrossRef] [PubMed]

21. MacLachlan, M.; Banes, D.; Bell, D.; Borg, J.; Donnelly, B.; Fembek, M.; Ghosh, R.; Gowran, R.J.; Hannay, E.; Hiscock, D.; et al. Assistive technology policy: A position paper from the first global research, innovation, and education on assistive technology (GREAT) summit. Disabil. Rehabil. Assist. Technol. 2018, 13, 454-466. [CrossRef] [PubMed] 
22. Henschke, C. Provision and financing of assistive technology devices in Germany: A bureaucratic odyssey? The case of amyotrophic lateral sclerosis and Duchenne muscular dystrophy. Health Policy 2012, 105, 176-184. [CrossRef]

23. Layton, N. Problems, policies and politics: Making the case for better assistive technology provision in Australia. Disabil. Rehabil. Assist Technol. 2015, 10, 240-244. [CrossRef] [PubMed]

24. Durocher, E.; Wang, R.H.; Bickenbach, J.; Schreiber, D.; Wilson, M.G. "Just access"? Questions of equity in access and funding for assistive technology. Ethics Behav. 2017, 29, 172-191. [CrossRef]

25. Bartlett, R.; Brannelly, T.; Topo, P. Using GPS technologies with people with dementia. Tidsskr. Omsorgsforskning 2019, 5, 84-98. [CrossRef]

26. Layton, N.; Steel, E. The convergence and mainstreaming of integrated home technologies for people with disability. Societies 2019, 9, 69. [CrossRef]

27. Finn, M. Implementering af elektronisk omsorgsjournal i kommunal setting. Tidsskr. Omsorgsforskning 2019, 5, 21-35. [CrossRef]

28. Johannessen, T.B.; Holm, A.L.; Storm, M. Trygg og sikker bruk av velferdsteknologi i hjemmebasert helse- og omsorgstjeneste. Tidsskr. Omsorgsforskning 2019, 5, 71-83. [CrossRef]

29. Frennert, S.; Baudin, K. The concept of welfare technology in Swedish municipal eldercare. Disabil. Rehabil. 2019. [CrossRef] [PubMed]

30. Frennert, S. Lost in digitalization? Municipality employment of welfare technologies. Disabil. Rehabil. Assist. Technol. 2018. [CrossRef] [PubMed]

31. WHO. Implementation of Assistive Technology GATE 5 p's. Available online: https://www.who.int/phi/ implementation/assistive_technology/phi_gate/en/ (accessed on 10 December 2019).

32. Lofqvist, C.; Slaug, B.; Ekstrom, H.; Kylberg, M.; Haak, M. Use, non-use and perceived unmet needs of assistive technology among Swedish people in the third age. Disabil. Rehabil. Assist. Technol. 2016, 11, 195-201. [CrossRef]

33. Ricky, B.; Natasha, L. Innovation in assistive technology: Voice of the user. Societies 2019, 9, 48. [CrossRef]

34. Coulter, A. Patient-centered decision making: Empowering women to make informed choices. Women's Health Issues 2001, 11, 325-330. [CrossRef]

35. Fors, A.; Blanck, E.; Ali, L.; Ekberg-Jansson, A.; Fu, M.; Kjellberg, I.L.; Mäkitalo, Å.; Swedberg, K.; Taft, C.; Ekman, I. Effects of a person-centred telephone-support in patients with chronic obstructive pulmonary disease and/or chronic heart failure-A randomized controlled trial. PLoS ONE 2018, 13, e0203031. [CrossRef]

36. Ranada, A.L.; Lidstrom, H. Satisfaction with assistive technology device in relation to the service delivery process-A systematic review. Assist. Technol. 2019, 31, 82-97. [CrossRef]

37. Tebbutt, E.; Brodmann, R.; Borg, J.; MacLachlan, M.; Khasnabis, C.; Horvath, R. Assistive products and the Sustainable Development Goals (SDGs). Glob. Health 2016, 12, 79. [CrossRef]

38. Wickström, G.; Regner, Å.; Micko, L. Vision eHealth 2025-Common Starting Points for Digitization in Social Services and Health and Medical Care. Affairs. Available online: https://www.ehalsomyndigheten.se/ globalassets/dokument/vision/vision-for-ehealth-2025.pdf (accessed on 10 December 2019).

39. Borg, J.; Larsson, S.; Östergren, P.O. The right to assistive technology: For whom, for what, and by whom? Disabil. Soc. 2011, 26, 151-167. [CrossRef]

40. Tangcharoensathien, V.; Witthayapipopsakul, W.; Viriyathorn, S.; Patcharanarumol, W. Improving access to assistive technologies: Challenges and solutions in low-and middle-income countries. WHO South-East Asia J. Public Health 2018, 7, 84. [CrossRef] [PubMed]

41. Ertner, M. Different generalizations of the elderly in design of welfare technology. Sts Encount.-Dasts Work. Paper Ser. 2016, 8, 1-28.

42. Garcon, L.; Khasnabis, C.; Walker, L.; Nakatani, Y.; Lapitan, J.; Borg, J.; Ross, A.; Velazquez Berumen, A. Medical and assistive health technology: Meeting the needs of aging populations. Gerontologist 2016, 56, S293-S302. [CrossRef] [PubMed]

43. Frennert, S.; Östlund, B. Narrative review: Technologies in eldercare. Nord. J. Sci. Technol. Stud. 2018, 6, 21-34. [CrossRef]

44. Bergschöld, J.M. Domesticating homecare services; Vehicle route problem solver displaced. Nord. J. Sci. Technol. Stud. 2016, 4, 41-53. [CrossRef] 
45. Realdon, O.; Rossetto, F.; Nalin, M.; Baroni, I.; Cabinio, M.; Fioravanti, R.; Saibene, F.L.; Alberoni, M.; Mantovani, F.; Romano, M. Technology-enhanced multi-domain at home continuum of care program with respect to usual care for people with cognitive impairment: The Ability-TelerehABILITation study protocol for a randomized controlled trial. BMC Psychiatry 2016, 16, 425. [CrossRef]

46. Rosenberg, L.; Kottorp, A.; Nygård, L. Readiness for technology use with people with dementia: The perspectives of significant others. J. Appl. Gerontol. 2012, 31, 510-530. [CrossRef]

47. Malinowsky, C.; Rosenberg, L.; Nygård, L. An approach to facilitate healthcare professionals' readiness to support technology use in everyday life for persons with dementia. Scand. J. Occup. Ther. 2014, 21, 199-209. [CrossRef]

48. Borg, J.; Ostergren, P.O. Users' perspectives on the provision of assistive technologies in Bangladesh: Awareness, providers, costs and barriers. Disabil. Rehabil. Assist Technol. 2015, 10, 301-308. [CrossRef]

(C) 2020 by the authors. Licensee MDPI, Basel, Switzerland. This article is an open access article distributed under the terms and conditions of the Creative Commons Attribution (CC BY) license (http://creativecommons.org/licenses/by/4.0/). 